\title{
Physical chemistry and functional materials: 2019
}

Published online: 20 January 2020

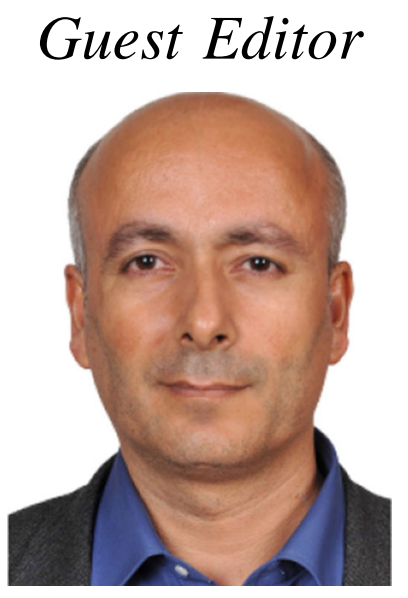

Dr. Niyazi Bulut

Faculty of Science, Firat University, 23119 Elazig, Turkey

This compilation is based on the peer-reviewed and selected papers on PCFM 2019. 


\section{Preface}

\section{Niyazi Bulut ${ }^{1}$}

This Special Chapter of Journal of Thermal Analysis and Calorimetry describes the selected papers from the 'Physical Chemistry and Functional Materials,' the PCFM 2019 Conference, a series of international conference suggested by Prof. Niyazi Bulut, who comes from the Physics Department of Firat University. As a pioneer of chemical dynamics and functional materials study in Turkey, Prof. Niyazi's group has done many important works in the fields of physics, chemistry, and material science, which has been widely recognized by international peers.

The PCFM 2019 Conference reflects the outstanding research being done in Europe and around the world by bringing together scientist from different countries and professional backgrounds to exchange ideas, advance knowledge, and discuss key issues for physical chemistry and material science.
This Special Chapter covers high-quality papers including all aspects of thermal analysis, thermogravimetry, derivative thermogravimetry, differential thermal analysis, thermodilatometry, differential scanning calorimetry of all types, thermomechanical analysis, thermal conductivity, multiple techniques, and miscellaneous thermal methods theory and instrumentation for thermal analysis and calorimetry.

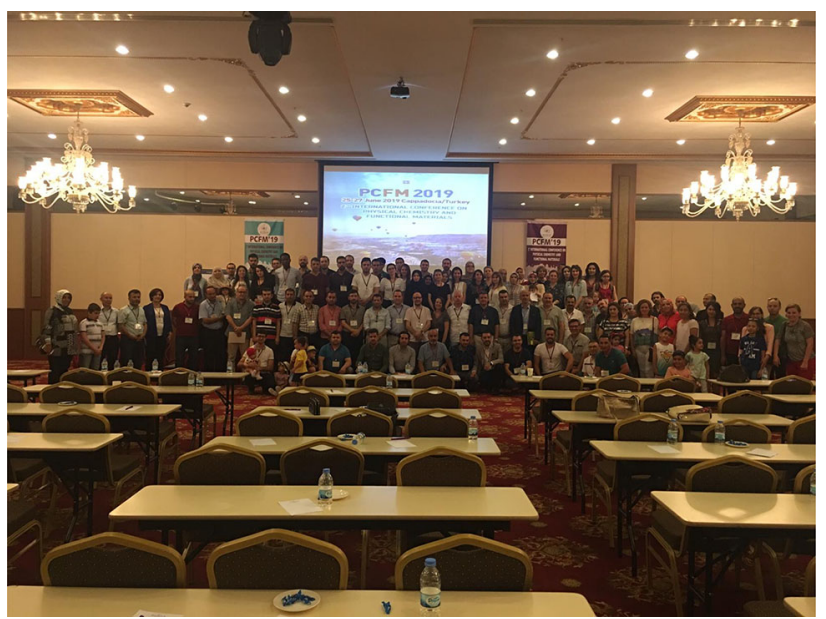

Niyazi Bulut

bulut_niyazi@yahoo.com

1 Faculty of Science, Firat University, 23119 Elazig, Turkey 


\section{Acknowledgements}

The Guest Editor is very grateful to the following scientists for their critical and valuable reviews which have significantly contributed to the quality of the papers in this Special Chapter:

Abbasi, S., Iran

Anjanapura, R. V., India

Dagdelen, F., Turkey

Flores, A., Mexico

Gunduz, B., Turkey

Guo, C., USA

Honcova, P., Czech Republic

Kaygili, O., Turkey

Kök, M., Turkey

Moudgil, K., USA
Ozdemir, N., Turkey

Pielichowski, K., Poland

Rodrigues, R. V., Brazil

Soykan, C., Turkey

Suñol Martinez, J. J., Spain

Yahia, I. S., Egypt

Yildiz, K., Turkey

Publisher's Note Springer Nature remains neutral with regard to jurisdictional claims in published maps and institutional affiliations. 